\title{
Coconut oil and palm oil's role in nutrition, health and national development: A review
}

\author{
Laurene Boateng, Richard Ansong, William B. Owusu and Matilda Steiner-Asiedu \\ Ghana Med J 2016; 50(3): 189-196 DOI: http://dx.doi.org/10.4314/gmj.v50i3.11
}

Department Of Food Science And Nutrition, University Of Ghana, P. O. Box LG 134, Legon, Accra, Ghana

Corresponding author: Laurene Boateng

E-mail: lboateng@chs.edu.gh

Conflict of interest: None declared

\begin{abstract}
SUMMARY
Coconut and palm oils which were the major sources of dietary fats for centuries in most of West Africa have been branded as unhealthy highly saturated fats. Their consumption has been peddled to supposedly raise the level of blood cholesterol, thereby increasing the risk of coronary heart disease. This adverse view has led to a reduction in their consumption in West Africa and they have been substituted for imported vegetable oils. Recent information however, indicates some beneficial effects of these oils particularly their roles in nutrition, health and national development. There is the need for a better understanding of their effects on health, nutritional status and national development. This paper therefore attempts to review the roles which coconut and palm oils play in these respects in developing countries, as a means of advocating for a return to their use in local diets.
\end{abstract}

Funding: None declared

Keywords: Palm oil, coconut oil, nutrition, health, national development

\section{INTRODUCTION}

Historically, dietary fats and oils have engendered considerable debate regarding type and optimal amounts used in the diet, their role in regulating body weight and their importance in the aetiology of chronic disease. ${ }^{1}$ Despite the contentious issues surrounding dietary fats, they are considered essential nutrients because they are required to perform critical functions in the body including serving as a carrier of preformed fat-soluble vitamins, enhancing the bioavailability of fat-soluble micronutrients and providing essential substrate for the synthesis of metabolically active compounds (such as the steroid hormones, testosterone, oestrogen and progesterone) among other useful functions. These benefits of fats notwithstanding, diets that are high in fat are strongly associated with an increased prevalence of obesity and an increased risk of developing coronary artery disease, high blood pressure, diabetes mellitus, and certain types of cancer. ${ }^{2}$

In Ghana, the prevalence of these chronic noncommunicable diseases and their risk factors have increased over time and have contributed significantly to the Ghana's disease burden. ${ }^{3,4}$
Hypertension, stroke, diabetes and cancers have recently reported as being among the top 10 causes of death in the country. ${ }^{4}$ Prevalence of hypertension currently stands at $13 \% \%^{5}$ whereas the prevalence of diabetes and hyperlipidaemia in Accra and Kumasi, two major cities, are reported to be ranging between $4 \%-9 \%$ and $17 \%$ $23 \%$ respectively. ${ }^{6}$ Since obesity is the forerunner of many of these non-communicable diseases (NCDs) and consumption of dietary fats and oils in turn play a key role in the development of obesity, it is important to understand what roles these oils play in our diets, health and national development.

In Africa, much of the fat content of traditional diets comes from plant oils such as red palm oil, groundnut oil, coconut oil and sesame oil. ${ }^{7}$ Whole-grain cereals also contribute some oils to the diet, especially when the cereal germ is not separated from the grain before milling. Two of the most important edible oils in the subSaharan Africa, are coconut oil and palm oil. Along with palm kernel oil, they are often referred to collectively, as the tropical oils and are typically known to be rich in saturated fats. 


\section{Special Article}

Palm oil, the oil obtained from the oil palm tree (Elaeis guineensis) is one of the most widely used cooking oils in West African countries. ${ }^{8}$

Coconut oil obtained from the coconut tree (Cocos nucifera), also finds extensive use in tropical and subtropical regions of the world for food and industrial purposes. The coconut oil traditionally produced in West Africa is made by crushing and pressing copra to extract the oils. This is done in large mills and the oil is freely available on the market. Palm kernel oil (which is not the focus of this article) is also produced by first cracking the palm kernel nuts either manually or mechanically, to separate the shells from the kernels. The kernels are then roasted and milled before the extraction of the oil. Berget ${ }^{9}$ however notes that in Ghana and much of West Africa, palm kernel oil is not consumed locally as a food oil to any significant degree. Local uses are limited to lamp oil and a local soap industry'.

DebMandal and Mandal $^{10}$ report that, in the United States, coconut oil was one of the major sources of dietary fats, aside from diary and animal fats, prior to the advent of the American edible oil industry in the 1940s. Despite the wide use of these tropical oils in less endowed countries, Enig ${ }^{11}$ reports however that, the coconut oil industry has suffered more than three decades of abusive rhetoric from consumer activist groups and organisations such as Centre for Science in the Public Interest (CSPI) and the American Soybean Association (ASA) and other members of the edible oil industry, as well as from those in the medical and scientific community who learned their apparent misinformation from these groups. Needless to say, palm oil has suffered a similar fate. According to Chong and $\mathrm{Ng}^{12}$, the principal allegation levelled against palm oil is that it is a highly saturated fat and its consumption supposedly raises the levels of blood cholesterol, thereby increasing the risk of coronary heart disease.

From the above, it is clear, that the saturated fat content of both coconut oil and palm oil have been the basis of the vilification campaigns against their use. Enig ${ }^{11}$ traces the origins of the anti-saturated fat campaign to the late 1950s, when a researcher in Minnesota announced that the heart disease epidemic was being caused by hydrogenated vegetable fats. The edible oil industry's response at that time was to claim that it was only the saturated fat in the hydrogenated oils that was causing the problem. This was followed by various forms of anti-saturated fat/anti- tropical oils campaigns (from the 1960s through to the mid-1980s) by individual researchers, some multinational companies and even governmental agencies in the United States. Chong and $\mathrm{Ng}^{12}$ however, noted that, the anti-palm oil (anti-tropical oil) campaigns in the United States were conducted more for economic gains than for genuine concerns of the health of the Americans. Sadly, this adverse publicity of tropical oil in the United States, has spread worldwide, even to countries in the developing world, with heart disease prevalence far lower than that of the United States.

Furthermore, in the developing world, this adverse publicity is characterized by pressure from all fronts including governmental agencies and health professionals (including nutritionists) to reduce consumption of oils such as palm and coconut oils. It is true that the phenomenon of the 'double burden of disease' is assuming unprecedented proportions in the developing world and the incidence of chronic disease is increasing steadily and even catching up with figures from the developed world. However, this increase in chronic disease has been attributed more to the 'westernization' of diets rather than the consumption of tropical oils, since these fats have been the mainstay (of edible oils) in many developing countries (especially in West Africa) for centuries. This, dating back even to the period when chronic disease prevalence was extremely low. Rather, the vilification of coconut and palm oils may be contributing to a situation where there is increased food insecurity (because individuals feel pressured to switch to less affordable and so called 'healthier' oils) and decreased quality of the food supply. This has resulted subsequently in hunger in areas of the developing world where there is shortage of energy and nutrients.

The aim of this paper is thus to contest the negative publicity that coconut and palm oils have suffered, via exploring their unique potential roles in the nutritional and health status of the less endowed peoples of the world, (particularly those from the West African Subregion), and in improving food security to enhance national development.

\section{Nutritional Profile and Metabolism of Dietary Fats - Palm and Coconut Oils in Perspective}

Fats and oils are concentrated forms of energy and the energy yield from the complete oxidation of fatty acids is about $9 \mathrm{kcal}$ per gram, in comparison with about 4 kcal per gram for carbohydrates and proteins. Triglycerides, are the most abundant fats found in foods. They are molecules made of fatty acids (chain-like molecules of carbon, hydrogen, and oxygen) linked in groups of three to a backbone of glycerol. When foods containing fats are consumed, the fatty acids are separated from their glycerol backbone during the process of digestion. Fats and oils in the diet are thus available to the body as fatty acids. 


\section{Special Article}

Fatty acids differ from one another in two ways-in chain length and in the degree of saturation.

With respect to degree of saturation, fatty acids can be classified as saturated (SFA), monounsaturated (MUFA) and poly-unsaturated (PUFA) fatty acids.

Saturated fatty acids, or saturated fats, consist of fatty acids whose carbon chain is "saturated" with hydrogen. These fats are found primarily in foods of animal origin — meat, poultry, dairy products, and eggs — and in coconut, palm, and palm kernel oils. High intake of saturated fats is associated with increased risk of coronary artery disease. $^{2}$

Monounsaturated fatty acids are fatty acids that lack one pair of hydrogen atoms on their carbon chain. Foods rich in monounsaturated fatty acids include canola, nut, and olive oils; they are liquid at room temperature. A diet that provides the primary source of fat as monounsaturated fat (frequently in the form of olive oil) and includes only small amounts of animal products has been linked to a lower risk of coronary artery disease, ${ }^{13}$

Polyunsaturated fatty acids lack two or more pairs of hydrogen atoms on their carbon chain. Safflower, sunflower, sesame, corn, and soybean oil are among the rich sources of polyunsaturated fats (which are also liquid at room temperature).

Trans fatty acids (TFAs) are another type of fatty acids, which are either naturally occurring or can be industrially produced in commercial quantities by a process known as hydrogenation. Hydrogenation involves the treatment of fats and oils with hydrogen gas in the presence of a catalyst resulting in the selective addition of hydrogen to the carbon to carbon double bonds. ${ }^{13}$

In industry, TFAs are created when vegetable oils (mainly the polyunsaturated oils) are partially hydrogenated to convert large numbers (typically 30-60\%) of naturally occurring cis unsaturated double bonds into trans unsaturated double bonds. ${ }^{14}$ A high TFA content provides physical and chemical properties that are attractive to food manufacturers. ${ }^{14}$ However, the consumption of these industrially produced partially hydrogenated vegetable oils is reported to be associated with an increased risk of cardiovascular disease, infertility, endometriosis, gallstones, Alzheimer's disease, diabetes and some cancers. ${ }^{15}$ TFAs also occur naturally in dairy products and meats of ruminants, but it is reported that human consumption is generally low and there is evidence to suggest that it does not adversely affect health. ${ }^{15}$
The details of population dietary guidelines for the quality and quantity of fat intake differ between countries. However, in consideration of prevention of CHD, dietary guidelines generally reflect advice to reduce average total fat intakes to $30-35 \%$ dietary energy and to lower saturated fat intakes to approximately $10 \%$ of dietary energy, ${ }^{1}$ and consumption of trans fatty acids be as low as possible. ${ }^{16}$

Palm oil which is obtained from the mesocarp of the palm fruit, is composed of $50 \%$ saturated fatty acids, $40 \%$ monounsaturated fatty acids and $10 \%$ polyunsaturated fatty acids. ${ }^{8}$ The saturated fat components are trace amounts of lauric and myristic acids, and a large amount of palmitic acid (44\%). ${ }^{17}$ It is important to note then that, of the saturated fatty acids found in diet, lauric and myristic acids (found only in trace amounts in palm oil) have more potential to raise total and LDL cholesterol concentrations whilst palmitic acid (found in abundance in palm oil) is less potent in that regard. ${ }^{1}$ Furthermore, palm oil is used directly in a variety of food processes without undergoing a hydrogenation process, in which some of the cis-double bonds are transformed to the trans-configuration. Therefore, it is worth noting that palm oil does not contain any trans- unsaturated fatty acid isomers. ${ }^{8}$ Indeed, Sundram, Sambanthamurthi ${ }^{17}$ have reported that, when palm oil is consumed as part of a low-fat diet ( $<30 \%$ energy), it has been shown to be effective in maintaining desirable plasma cholesterol and lipoprotein cholesterol levels. The principal triglyceride species in palm oil have palmitic acid at the alphaposition of the molecule, and this location confers the non-hypercholesterolaemic property to the oil. ${ }^{8}$

When fat is eaten, it must first be digested before it can be absorbed through the intestinal wall. Most of the digestion of fat occurs in the upper part of the small intestine and is accomplished by special digestive enzymes called lipases which act on fat (triglycerides) that has been emulsified with the aid of bile acids. The lipases work by breaking the emulsified fat into smaller units. Some of the fat that is "digested" is broken down into individual fatty acids and glycerol whilst some is broken down into the special intermediate molecules called monoglycerides, which are made of glycerol with one remaining fatty acid still attached. These monoglycerides are absorbed as such. By the time some of these fatty acids monoglycerides and glycerol have travelled through the intestinal cell to the lymph stream, they are repackaged into triglycerides.

The duration of fat digestion and absorption depend on the length of the fatty acid chain. The fatty acid chains can be classified into long chain fatty acids (LCFAs), medium chain fatty acids (MCFAs) and short chain fatty 


\section{Special Article}

acids (SCFAs). As indicated earlier in this review, in the past four decades misinformation and disinformation provided by certain politically biased agricultural groups and repeated in both the professional and lay press have led people to believe that all saturated fats are unhealthy. ${ }^{18}$

Little attention is focused on the fact that saturated fatty acids are not a single family of fats but comprise the three subgroups; short- (C2-C6), medium- (C8-C12) and long- (C14-C24) chain fatty acids.

The fat molecules that have long chain fatty acids (LCFAs) are ultimately transported by carriers in the lymph system called chylomicrons, which are manufactured in the intestinal cells for the purpose of transporting these exogenous fat molecules. The triglycerides are transported by the chylomicrons to the liver or to other tissues. Once those triglycerides (and their fatty acids) enter the cells, they are again broken apart into increasingly smaller units until they are formed into the final energy molecule called ATP. This is an oxidative process. Sometimes the oxidation takes place in the peroxisomes but will usually take place in the mitochondria. If the cells do not immediately need the energy molecule, the small units that have been formed are shunted into the synthesis of fatty acids, and then as triglycerides, they are stored in adipose tissue.

The slow digestion of fat allows for the gradual release of energy so that there is no need for the liver and adipose tissue to synthesize fat. This slow digestion of fat also helps the body to absorb more of the nutrients that come along with the fat. The short chain fatty acids (SCFAs) and most of the medium-chain fatty acid (MCFA) molecules, on the other hand, go into the portal blood and are transported to the liver in much the same way that the carbohydrate goes to the liver. These shortchain and medium-chain fatty acid molecules also supply energy more rapidly like carbohydrates. The different absorption behaviour of the short and medium-chain fatty acids is exploited for dietetic purposes. Since they are not re-esterified inside the intestinal mucosa and are bound to and transported with albumin in the blood directly, they often represent the only option for fat absorption in patients whose fatty acid absorption mechanisms are defective. Furthermore, they have the advantage of being absorbed quantitatively in the intestinal lumen, even with reduced lipase activity. Herein lies the uniqueness of coconut oil. Coconut oil is made up of about $90 \%$ saturated fats and $9 \%$ unsaturated fats. However, the saturated fats in it differ from saturated fats in animal fats. Over $50 \%$ of the fats in coconut oil are medium chain fatty acids, such as lauric acid (12:0). Coconut oil is the highest natural source of lauric acid. Lauric acid and its derivative monolaurin constitute around $50 \%$ of coconut fat-derived lipid.

However, unlike long chain fatty acids, these medium chain free fatty acids and monoglycerides are absorbed intact from the small intestine, and do not undergo degradation and re-esterification processes. They are directly used in the body to produce energy, and widely used in infant formulas, nutritional drinks for athletes and intravenous lipid infusions. ${ }^{19}$

\section{Nutritional and Functional Properties of Coconut and Palm Oils - Roles in Enhancing Food and Nutri- tion Security}

The majority of undernourished people live in the developing economies. FAO $^{20}$ has reported that the proportion of undernourished people is highest in subSaharan Africa, where it is estimated at 30 percent. Interestingly, many African countries who are still battling poverty, food insecurity, undernutrition, and infectious diseases including the HIV/AIDS epidemic are currently faced with increasing levels of overweight and obesity, leading to a coexistence of undernutrition and overnutrition with their attendant ramifications, popularly known as the 'double burden of disease'. Prentice ${ }^{21}$ partly attributes the emerging obesity phenomenon in Africa to the transformation of the range of goods sold in the village shops. Prominent among these are large yellow plastic containers of imported vegetable oils. Throughout Africa these oil containers are recycled as water carriers and have completely displaced the metal kerosene drums that used to fulfil this function, thus providing a vivid visual picture of this one key component of the nutrition transition.

Palm and coconut oils possess remarkable nutritional and functional properties that can be employed to the advantage of the developing countries like Ghana. West African societies have a long history of recognizing palm oil as a nutritional haven - it has been used as a primary source of dietary fat as well as a remedy for illnesses. $^{22}$ Dietary fats are crucial sources of energy for particularly infants and children in developing countries, and palm oil plays a crucial role as it is commonly used in many stews, gravies and soups eaten with starchy staples in Ghana.

Aside fats, the major nutrient which palm oil contributes to the diet, Wattanapenpaiboon and Wahlqvist ${ }^{8}$ outline the following minor but nutritionally beneficial components of palm oil;

a) Palm oil contains $\alpha-, \beta$ - and $\gamma$-carotenes. These are precursors of vitamin $\mathrm{A}$, which prevents night blindness, aids maintenance of tissues and promotes growth. In developing countries like Ghana where vitamin A deficiency is a 


\section{Special Article}

major problem among both adults and children, using palm oil in meals in moderate amounts is a relatively affordable means of ensuring adequate vitamin A intake.

b) Palm oil contains phytosterols such as sitosterol, stigmasterol and campesterol. These lipophilic sterols are easily absorbed in the gastrointestinal tract, and then converted through a series of enzymatic reactions into cholesterol, which is a major precursor of steroid hormones.

c) Squalene, present in palm oil, when in excess amounts has been found to possess a negative feedback inhibition activity on the function of HMG-CoA reductase, an enzyme involved in the production of cholesterol in the liver. Thus, a moderate use of palm oil is likely to be beneficial for blood lipid profiles.

d) Palm oil is rich in vitamin E, which is composed mainly of tocopherols and tocotrienols. These compounds act as potent antioxidants that make it relatively stable to oxidation. Both animal and human studies show that tocotrienols could reduce plasma cholesterol, apolipoprotein B, thromboxane B2, and platelet factor IV. They could also inhibit or delay the oxidative deterioration of cellular membranes. This makes palm oil protective against chronic conditions like cancer which is currently emerging in developing countries like Ghana.

The above benefits notwithstanding, one recently identified drawback that could jeopardize the use of palm oil in developing countries such as Ghana is the adulteration of palm oil with the high levels of Sudan IV dye, a chemical reported to have carcinogenic potential. The Daily Graphic newspaper in Ghana reports the confiscation of large quantities of palm oil from several markets in Accra by the Food and Drugs Authority (FDA) following positive laboratory tests indicating their contamination with Sudan IV dye. ${ }^{23}$ The FDA's regulatory measures if diligently pursued and sustained should hopefully curb this negative trend and thus prevent palm oil from being further maligned, this time, on account of its safety.

Coconut oil has been shown to have the potential to protect against not only heart disease but a wide variety of chronic health problems including diabetes and cancer as well as a means to prevent and even treat infectious diseases, however, knowledge about coconut oil has been kept buried in medical journals because of a general prejudice against saturated fats. ${ }^{24}$
Coconut oil is composed of the fatty acids, caprylic acid C -8:0 (8\%), capric acid, C-10:0,(7\%), lauric acid C12:0, (49\%), myristic acid C-14:0(8\%), palmitic acid C16:0 (8\%), stearic acid C-18:0 (2\%), oleic acid C-18:1 $(6 \%)$ and $2 \%$ of $\mathrm{C}-18: 2$ linoleic acid .

DebMandal and Manda ${ }^{10}$ report that coconut oil is rich in medium chain saturated fatty acids (lauric acid) which allows them to be directly absorbed from the intestine and sent straight to the liver to be rapidly used for energy production and thus MCFAs do not participate in the biosynthesis and transport of cholesterol. This cardio-protective attribute of coconut oil can be taken advantage of by developing countries in West Africa that are grappling with the nutrition transition with its attendant upsurge of chronic diet-related diseases including obesity and heart disease. Fife ${ }^{24}$ reports that in Sri Lanka, coconut had been the primary source of dietary fat for thousands of years. In 1978 the per capita consumption of coconut was equivalent to 120 nuts/year. At that time the country had one of the lowest heart disease rates in the world. Only one out of every 100,000 deaths was attributed to heart disease, whereas in the United States of America, where very little coconut was eaten and people relied more on polyunsaturated oils, the heart disease death rate at the same time was at least 280 times higher. As a result of the 'antisaturated fat' campaign coconut consumption in Sri Lanka has declined since 1978. By 1991 per capita consumption had dropped to 90 nuts/year and has continued to fall. In place of coconut oil the people begun to eat more corn oil and other polyunsaturated vegetable oils. As coconut consumption decreased, heart disease rates increased in Sri Lanka and interestingly, the problem was greater in the urban cities ${ }^{24}$. This Sri-Lankan scenario could well be playing out in many developing countries in West Africa.

DebMandal and Manda ${ }^{10}$ further report, that coconut oil is very effective against a variety of lipid-coated viruses such as visna virus, CMV, Epstein-Barr virus, influenza, virus, leukemia virus, pneumo virus and hepatitis $\mathrm{C}$ virus. The MCFA in coconut oil primarily destroys these organisms by disrupting their membranes, thus interfering with virus assembly and maturation. Control of infections is crucial on the health agenda of many developing countries in West Africa, and the use of coconut oil could serve as a cheaper alternative means of controlling infections.

In West African diets, coconut and palm oils are often used for frying. When cooking oils are heated, reactions such as oxidation, hydrolysis, isomerisation and polymerisation occur, resulting in the formation of a variety of volatile compounds and monomeric and pol- 


\section{Special Article}

ymeric products ${ }^{26,27}$ some of which are potentially toxic. ${ }^{28}$ Some of these oxidised volatile products (eg acrolein and other $\alpha, \beta$-unsaturated aldehydes) are known to be responsible for the off-flavour and negative effects on human health. ${ }^{26,27}$

This makes it important to highlight the attribute of the smoke point of these oils. The smoke point is the temperature at which a fat or oil produces a continuous wisp of smoke and is a useful indicator of an oil or fat's suitability for frying. ${ }^{28}$

A general rule is that, fats with a higher smoke point are better suited for deep frying, whilst fats with a smoke point below $200{ }^{\circ} \mathrm{C}$ are not. ${ }^{27}$ The smoke point of unrefined palm oil is $235{ }^{\circ} \mathrm{C}$ whilst that of unrefined coconut oil is $177{ }^{0} \mathrm{C} .{ }^{29}$ In this light coconut oil is better suited for shallow frying, which is done at much lower temperatures, ${ }^{28}$ whilst palm oil on the other hand is suitable for both deep and shallow frying. ${ }^{30}$

The smoke point is related to the free fatty acid content of oils, thus reheating (re-use) of oils is not recommended as used oils will contain a higher free-fatty acid content, with a consequent decrease in its original smoke point, which will result in higher emissions of volatile compounds at lower temperatures. ${ }^{27}$

Proper ventilation in kitchens is also beneficial in reducing the impact of these potentially toxic volatile compounds. ${ }^{27}$ It is imperative for dietitians and nutritionists to be familiar with this attribute of the oils in order to better educate consumers on their appropriate use.

\section{Role of Palm Oil and Coconut Oil in National Devel- opment}

Agriculture employs 65 percent of the workforce in Sub-Saharan Africa. Therefore, the continued expansion of productive and high yield agriculture is essential for the reduction of poverty in Africa ${ }^{31}$ and consequently the acceleration of national development. The production of palm and coconut oils hold promise and represent one of the most effective methods of hoisting developing nations like countries in Sub-Saharan Africa out of poverty, and ensuring food security.

The large scale manufacture of these oils is sure to provide employment for millions of unskilled and semiskilled workers. With respect to palm oil production in West Africa, Thompson, ${ }^{31}$ reports that Nigeria is currently the third largest producer of palm oil in the world after Indonesia and Malaysia and palm oil production provides jobs for at least 1.8 million Nigerians.
In spite of this impressive profile, Nigeria remains a net importer - its local production is not up to demand, thus Nigeria at present does not export palm oil. The local shortfall is being supplemented by imports from countries such as Malaysia and Indonesia. ${ }^{31}$

Nigeria thus remains the largest producer of palm oil in West Africa. Incidentally, Ghana, which also has a long history of palm oil production has apparently failed to take it beyond mere potential, due to the use of traditional methods of production coupled with the low quality of palm oil produced which could not make Ghana to meet up with the rising global and domestic demand. ${ }^{31}$ The ministry of food and agriculture website also indicates that, palm oil production, based on small-scale production, was a leading foreign exchange earner for Ghana from about the mid-nineteenth century to the beginning of the twentieth century. ${ }^{32}$

Lessons from strides being made in the palm oil industry in Nigeria however indicate that, if developing economies including both Ghana and Nigeria, will focus some more resources on the sustainable production of palm oil, which is reported to give the highest yield of oil per unit of any crop $^{33}$ and is also associated with relatively low production costs, ${ }^{31}$ it will be a highly effective means of alleviating poverty and accelerating development of our fledgling economies. Then we can join the ranks of nations like Indonesia and Papua New Guinea, where palm oil is a major foreign exchange earner. ${ }^{34}$ World Growth ${ }^{34}$ further reports that globally, about 3 million smallholder families (equivalent to about 15 million people) are involved in the palm oil sector. This is a step in the right direction and will provide a means of livelihood for small holders who continue to make significant contributions to national development worldwide. Unfortunately whilst the palm oil industry is being taken advantage of for economic gains in some parts of the world, Ghanaian oil palm farmers are threatening to abandon the oil palm (whose products fuel palm oil production) and switch to cultivation of rubber and other cash crops. They cite lack of financial support from government and banks, lack of appropriate pricing for their commodity and no input subsidies or state-sponsored extension services. ${ }^{35}$

The Malaysian Palm Oil Board (MPOB) of Malaysia, one of the largest producers of palm oil globally, have outlined some research and development goals intended to support the well-being of its oil palm industry as follows; to improve the production efficiency and quality of palm oil, kernel oil and biomass products; to expand and improve the current uses for oil palm products; to find new uses for oil palm products as a substitute; to promote the use, consumption and marketability of oil 
palm products; and ensure that the oil palm industry is environmentally-friendly. ${ }^{36}$

Governments of developing economies in sub-Saharan Africa, particularly Ghana, will benefit immensely from emulating the Malaysian example and should work towards collaborating with relevant stakeholders to spearhead a thriving oil industry, which will ultimately result in accelerated national development.

Coconut oil has always been known to the people of the Western Region of Ghana because of its immense contributions to individual households and communities. Almost every household particularly in 'Nzemaland' of that region, has something to do with coconut oil in one way or the other. Apart from using it to cook, coconutoil processing business has served as a major economic activity and generated employment for many.

The Nzema youth association website report that research into small-scale coconut oil processing industries in the Axim District found out how families have improved their living standard as a result of their engagement in the coconut oil business. These contributions, notwithstanding, disease and neglect of the industry have continually dogged coconut plantations in the Nzemaland, thereby gradually limiting the ability of these processors to continue in business. ${ }^{37}$

The establishment and support of coconut plantations by government and the relevant stakeholders, will not only add to the total economic GDP of the country, but will invariably make a positive impact on the income of the citizens in the coconut growing areas as well as their diets, thereby contributing to improved health and standards of living.

\section{CONCLUSION}

Although awareness of the health benefits of coconut and palm oils is becoming increasingly known, many Ghanaians still think of them as unhealthy arteryclogging saturated fats because of the negative antisaturated fat campaigns that have prevailed for decades. This notwithstanding, the images of coconut and palm oils are gradually evolving worldwide as unique oils, suitable for both edible and non-edible uses. Consistent messages from health researchers indicate that an overall healthful dietary pattern, rather than individual nutrients is beneficial in the quest for better health and in this context, Katz and Meller report that guidance that places an exaggerated emphasis on the exclusion or inclusion of any one food or nutrient is ill-advised. ${ }^{38}$ Health professionals, particularly dieticians and nutritionists therefore have key roles to play in educating consumers on overall healthy eating patterns, and that includes the appropriate use of these oils.

When prioritized and supported, the coconut and palm oil industries will not only provide foods, income and raw materials, but will also provide employment for the development of the nation. Some research has provided the groundwork for the production and use of these oils in Africa. However, more country-specific work remains to be done to find innovative solutions to make the coconut and palm oil industries profitable in the long term, as well as assess their benefits and impacts on human health, industry and the environment.

\section{ACKNOWLEDGEMENTS}

We thank our colleagues from Department of Nutrition and Food Science, University of Ghana, who provided feedback and insight that greatly improved this manuscript.

\section{REFERENCES}

1. Caballero B, Allen LH, Prentice A, editors. Encyclopedia of human nutrition. Oxford: Academic press; 2012.

2. Murdock D, editor. Encyclopedia of foods: a guide to healthy nutrition. California: Academic Press; 2002.

3. Aikins Ad-G. Ghana's neglected chronic disease epidemic: a developmental challenge. Ghana Med J. 2007;41(4):154.

4. de-Graft Aikins A, Addo J, Ofei F, Bosu WK, Agyemang C. Ghana's Burden of Chronic NonCommunicable Diseases: Future Directions in Research, Practice and Policy. Ghana Med J. 2012;46(2 Suppl):1-3.

5. GSS. Ghana Statistical Service (GSS), Ghana Health Service (GHS), and ICF International (2015). Ghana demographic and health survey 2014. Rockville, Maryland, USA: GSS, GHS, and ICF International.

6. Bosu W. Accelerating the Control and Prevention of Non-Communicable Disease in Ghana: The Key Issues. Postgraduate Med. J. of Ghana. 2013;2:3240.

7. FAO. Agriculture food and nutrition for Africa - A resource book for teachers of agriculture. Rome: FAO, 1997.

8. Wattanapenpaiboon N, Wahlqvist ML. Phytonutrient deficiency: the place of palm fruit. Asia Pac. $J$ Clin Nutr. 2003;12(3):363-8.

9. Bergert DL. Management strategies of Elaeis guineenis(oil palm) in response to localized markets in South Eastern Ghana, West Africa: Michigan Technological University; 2000. 
10. DebMandal M, Mandal S. Coconut (Cocos nucifera L.: Arecaceae): In health promotion and disease prevention. Asian Pac. J of Trop Med. 2011;4(3):241-7.

11. Enig MG, editor Coconut: in support of good health in the 21 st century. 36th meeting of APCC; 1999; Singapore.

12. Chong Y, Ng T. Effects of palm oil on cardiovascular risk. Med J Malaysia. 1991;46(1):41-50.

13. Chowdhury K, Banu LA, Khan S, Latif A. Studies on the fatty acid composition of edible oil. Bangladesh J. of Sci and Ind Res. 2007;42(3):311-6.

14. Mozaffarian D, Stampfer MJ. Removing industrial trans fat from foods. BMJ. 2010;340.

15. Downs SM, Thow AM, Leeder SR. The effectiveness of policies for reducing dietary trans fat: a systematic review of the evidence. Bulletin of the WHO. 2013;91:262-9h.

16. Kris-Etherton PM, Innis S, Ammerican DA. Position of the American Dietetic Association and Dietitians of Canada: dietary fatty acids. J. of the Am Dietet Assoc. 2007;107(9):1599-611.

17. Sundram K, Sambanthamurthi R, Tan Y-A. Palm fruit chemistry and nutrition. Asia Pac J. of Clin Nutr 2003;12(3):355-62.

18. Kabara JJ. Health oils from the tree of life. Nutritional and Health Aspects of Coconut Oil Indian Coconut J. 2000;31(8):2-8.

19. Assunção ML, Ferreira HS, dos Santos AF, Cabral Jr CR, Florêncio TM. Effects of dietary coconut oil on the biochemical and anthropometric profiles of women presenting abdominal obesity. Lipids. 2009;44(7):593-601.

20. FAO. Global Hunger Declining But Still Unacceptably High. Rome: Economic and Social Development Department, FAO; 2010.

21. Prentice AM. The emerging epidemic of obesity in developing countries. Int J. of Epid. 2006;35(1):939.

22. Chawla S, Saxena S. Red Palm Oil-Health Benefits And Their Molecular Executors. Int J. of Bioassays. 2013;2(09):1223-31.

23. Graphic online. FDA confiscates adulterated oil from 10 markets in Accra Ghana: Graphic Coporation; 2015 [cited 2015 October 29th]. Available from: http://www.graphic.com.gh/news/generalnews/fda-confiscates-adulterated-palm-oil-from-10accra-markets.html

24. Fife B, editor Coconut oil and health. ACIAR PROCEEDINGS; 2006; Cairns, Australia: ACIAR; 1998.

25. Yong JW, Ge L, Ng YF, Tan SN. The chemical composition and biological properties of coconut
(Cocos nucifera L.) water. Molecules. 2009;14(12):5144-64.

26. Esposto S, Taticchi A, Di Maio I, Urbani S, Veneziani G, Selvaggini R, et al. Effect of an olive phenolic extract on the quality of vegetable oils during frying. Food Chem. 2015;176:184-92.

27. Katragadda HR, Fullana A, Sidhu S, CarbonellBarrachina ÁA. Emissions of volatile aldehydes from heated cooking oils. Food Chem. 2010;120(1):59-65.

28. Gunstone F. Vegetable oils in food technology: composition, properties and uses: John Wiley \& Sons; 2011.

29. Culinary Institute of America. The New Professional Chef. 6 ed. New York: John Wiley \& Sons. ; 1996.

30. Matthäus B. Use of palm oil for frying in comparison with other high-stability oils. Europ J. of Lipid Sci and Tech. 2007;109(4):400-9.

31. Thompson A. African Case Study: Palm Oil and Economic Development in Nigeria and Ghana; Recommendations for the World Bank's 2010 Palm Oil Strategy. Initiative for Public Policy Analysis, 2010.

32. Ministry of Food and Agriculture. Master plan study on the oil palm industry in Ghana Ghana: Ministry of Food and Agriculture; 2011 [cited 2014 October 3rd]. Available from: http://mofa.gov.gh/site/?page_id=10244.

33. Edem D. Palm oil: Biochemical, physiological, nutritional, hematological and toxicological aspects: A review. Plant Food Hum Nutr. 2002;57(34):319-41.

34. World Growth. Palm Oil and Food Security: The impediment of Land Supply. Arlington, VA: 2010.

35. Business and Financial Times. The sorry state of oil-palm growers Ghana: Business and financial times; 2014 [cited 2014 October 3rd]. Available from:

http://www.ghanaweb.com/GhanaHomePage/News Archive/artikel.php?ID=299356.

36. Basiron Y, Weng CK. The oil palm and its sustainability. J. Oil Palm Res. 2004;16(1).

37. Nzema Youth Association. Oil in the motherland Ghana; 2011 [cited 2014 October 3rd ]. Available from:

http://nzemayouthassociation.wordpress.com/?s=co conut + oil.

38. Katz D, Meller S. Can we say what diet is best for health? Annu Rev Public Health. 2014;35:83103. 